\title{
Puppeteers, Performers or Avatars - A perceptual difference in telematic space
}

\author{
Paul Sermon
}

\section{The telematic performer role - a split dynamic}

Through descriptive accounts of my working practice and its general post-structuralist standpoint it is my intension to describe and convince the reader that the activity of an interactive art installation viewer is far more complex than simply becoming a user (or a browser) - a commonplace term for the new media art viewing public - associated with the activity of navigating through screen based interactive systems. Through the increasing interest in an open-systems approach to interactivity that embodies generative data and undefined personal experiences - as oppose to relying on a closed-system of finite variables that default back to there original state upon leaving the piece, the user is rapidly becoming a performer or actor within the new organic narrative environments defined through avatars and agents in both online screen based interaction and offline interactive environments, or as Andrea Zapp refers to as "story rooms" [1] - a mediated space that encapsulates its "performers" in a complex social interchange in the form of a new media narrative. This social move towards the public performer is commonplace at every cultural level from endless phone in radio stations to ubiquitous surveillance observation and the global domination of reality TV - perhaps best encapsulated in Peter Weir's The Trueman Show in 1998. In the same way that Lacan suggested the human psyche is constructed in the mirror - as if on stage in front of us, I am suggesting the method of identity construction is taking place on the new global media stage - and it is in the form of interactive telematic environments and their user determined narratives that we are able to become consciously aware of the performer role we are adopting at all social and cultural levels.

My work in the field of telematic arts explores the emergence of user-determined narrative between remote participants who are brought together within a shared telepresent environment. Through the use of live chroma-keying and videoconferencing technology these divided audience participants enter a video installation and initially suppose they entering a passive space - sitting, standing or sometimes lying within it. Their presence within the space is recorded live on video camera and mapped in real-time, via a chroma-key video mixer, with an identical camera view of another participant in an identical installation space - combining two shots of live action by replacing a blue or green back drop in one image with the image of the other. The two spaces which can be any geographical distance apart are linked via an $\mathrm{H} .323$ internet videoconference connection, making it possible to link and combine these telematic installations and there performing audiences between almost any location in the world.

This is essentially how all my installation projects function, but what is most surprising for the intended viewer is that they form an integral part within these telematic experiments, which simply wouldn't function without their presence and forced participation within it. The audience participant rapidly becomes a performer, or at best an actor within these spaces, by observing their body within a telepresent space represented on self-view video monitors in front of them. The user/actor ascends a rapid learning curve and begins to control and choreograph their human avatar representation of themselves in a new telematic space, in combination with another physically remote role-playing user. My main intension is to allow my audience to view and experience my work in both a passive and active role - drawing very different experiences and initial conclusions from them. Whilst in the passive viewing mode the audience is observing the public in what often 
appears to be a well rehearsed piece of drama confidently played out by actors - compelling viewing, but a complex issue to contend with when it is understood the performers are also audience members merely participating in an active role. Once the audience participant enters this space they immediately represent two dynamic performer roles; consciously as the controller, or puppeteer, of their own avatar performer, yet unaware of their secondary performing role to the off camera members of the audience. Who are themselves awaiting the next available slot on the telematic stage - soon to be sharing in this split dynamic. The Narrative that unfolds here would appear to be self determined by the user, on and off camera. But what is essential in such experiments is the architecture of this installation. As an artist I am both designer of the environment and director of the narrative, which I determine through the social and political context that I choose to play out these telepresent encounters in. This is exemplified in my installation “There’s no simulation like home” produced at Fabrica Gallery Brighton in 1999.

\section{There's no simulation like home}

The commission by lighthouse Media Centre Brighton and BN1 to produce this piece came at a time when I wanted to combine many of my previous telematic installations/experiments within one entire fabricated walkthrough environment, staged as a domestic interior of a house. Initially I intended on linking two identical "Barrat Show Homes", which often use identical blueprints for housing estates throughout the UK - ideally enabling me to link and combine the two spaces as one shared telematic environment. As always the concept changed for a number of reasons, including budget, and I started to develop the idea of completely reconstructing a domestic home interior as an entire stage set inside the Fabrica Gallery in Brighton. Consequently this new installation plan allowed more passive modes of viewing the active participants inside the installation to emerge via surveillance cameras and spy holes. At the time this was certainly influenced by Peter Weir's "The Trueman Show", whose main character "Trueman" (Jim Carrey) unconsciously displays an overacted melodramatic role in his supposed normal everyday private life - a personality whose temperament is developed and encouraged by his apparent performer friends and family that surrounded him. It was for the same intension that I chose to enhance and disguise the two modes of viewing and performing in the installation. The result of this division in modes of participation ultimately led me to present these ideas in this paper.

"There's no simulation like home" was the culmination of telepresent and telematic research since 1992. The exterior of the installation resembled the back of a plasterboard stage set, or as if the bricks of a house had been removed to reveal the back of the inner plasterboard skin. Electricity and video cables were traced and attached all around the surface of the structure, looking like the back of large circuit board. The installation was architectured on the typical floor plan of the English terraced house and by using a walk through narrative sequence, from front door to back door, the audience encounter differing telepresent interfaces in each of the four rooms: the living room sofa, the bedroom, the dining room table and the bathroom mirror. Before entering the installation the audience had the possibility to view the installation through a series of peepholes positioned along the plasterboard exterior. Offering a passive form of viewing other users who were already involved in the process of navigating the installation narrative as an actor within it.

Inside the installation the audience were encompassed within a simulated domestic home environment, exemplified in the dimensions of the rooms, the wood-chip wallpaper, the light fittings, skirting board and wall sockets. The living room sofa and television screen formed the first telematic link outside the installation space, where a second sofa and video monitor were located. By using a system of live chroma keying the two separate people, who could have been any distance apart, shared the same sofa on the same telepresent screen. In the bedroom the viewer could lie down on a bed onto which a live video projection was being made of another person, who was located outside the installation space on a second bed. A video image of the combined 
audiences together on the projection bed allowed the viewers to interact in a telepresent space by touching with their eyes, where a shift of senses occurs through the exchange of sight with the sense of touch - touching with your eyes as if you are touching with your hands. In the same way a blind person will improve and rely on the sensory inputs of sound and touch, the loss of tactile touch on the bed is compensated by the sense of sight. Not unlike the visual sensory input of pain that is often stimulated prior to the momentarily numbed nerve endings in the tissue at the cause of it - the cognitive process of pain taking place via the eyes, regardless of where they are located, or as cognitive scientist Daniel Dennett explains...

"Blindfold yourself and take a stick (or a pen or pencil) in your hand. Touch various things around you with this wand, and notice that you can tell their textures effortlessly - as if your nervous system had sensors out at the tip of the wand. Those transactions between stick and touch receptors under the skin (aided in most instances by scarcely noticed sounds) provide the information your brain integrates into a conscious recognition of the texture of paper, cardboard, wool, or glass. These successes must depend on felt vibrations set up in the wand, or on indescribable - but detectable - differences in the clicks and scrapping noises heard. But it seems as if some of your nerve endings were in the wand, for you feel the difference of the surfaces at the tip of the wand." [2]

In the case of the telepresent bed the stick or wand being the visual simulation of the body at a distance, placing your finger nerve endings in the telepresent body.

The exterior installation space communicated a contrasting image to the domestic interior. Unlike the inside, the technology was very visible - akin to a back-stage environment. The telepresent interfaces located on the outside of the installation, appeared as areas for interaction and observation of the experiment like situation taking place inside the installation. In keeping with the reference to the user/actor within the space and the observer of the performance outside the installation, video images from small surveillance cameras inside were constantly being displayed on monitors outside.

The dining room table was the third telematic interface to the outside installation. Offering a slightly less psychological complex platform for interaction by identifying different characteristics in user/performer behaviour, introducing telematic interaction in the forms of discussion and confrontation. Again working with a system of live chroma keying between two separate tables the remote viewer was able to sit at the same table in the same telepresent room. The final room and interface the user/actor confronted before exiting out the back door, was the bathroom mirror. What initially appeared to be a normal mirror lacked one essential truth - the viewer's own image. A momentary illusion that was broken only when the user realised the mirror was in fact a window into an identical room. Whilst the actor become accustomed to accept their existence in telepresent forms throughout the installation they were finally denied the most simple telepresent truth they expect from a mirror. As Lacan identifies in his mirror stage by putting the notion of the real and the virtual into question.

"We have only to understand the mirror stage 'as an identification', in the full sense that analysis gives to the term: namely, the transformation that takes place in the subject when he assumes an image." [3]

By representing the domestic reality inside the installation as a fabrication of the technological apparatus outside. "There's no simulation like home” attempted to present all realities as a construct of language. 


\section{“The visual and kinetic codes of proxemic relations.” - Margaret Mores}

Essential to all the interfaces in this installation is the use of nonverbal communication. By not using sound the user/performer is forced to communicate in a melodramatic style akin to a silent movie - bringing about an enforced use of gesture and body movement in order to communicate with the fellow participant. By restricting verbal communication the participant is further distanced from their telepresent reflected performer role, which allows a far less self-conscious experience in the space. Whilst the silent melodrama was introduced for precisely this reason, it also refers directly to Charlie Chaplin's comments on the end of cinema when sound was first introduced highlighting that the inadequacy of a technology is its single most creative potential. The following extract from Margaret Mores describes the process of induced mime and mimicry extremely accurately and has been influential to me in further opening up this discussion around user defined narratives.

"By not transmitting sound, Sermon has chosen to explore the visual and kinetic codes of proxemic relations, that is, the relative distance of human bodies in private/social exchange, rather than verbal exchanges. A cyberspace couple on the bed can interact in any way gesture allows. The dematerialization of gestures and objects tendered, far from undermining their meaning, makes images and actions naked of anything but symbolic meaning and all the more powerful therefore. Thus, the stage has been set for an exploration of the effect of symbolic acts on the psyche...." [4]

Specifically with the bed interface, the body has been turned into a visual interlocutor that is not only without the ability to have speech but also dominance, strength, smell and on occasions gender - depending on the clothing and concealed physique of the participant. Without these characteristics the performer is immediately persuaded to accept and interpret communication through touch with an otherwise complete stranger in a highly emotional and sensitive relationship. Morse further explains it:

“...Paul Sermon's experiments with "telematics" or "telepresence" continue research that began in the late 1960's using satellites to link live interaction in sound and image between two or more sites. This strand of experimentation also has predecessors in the closed-circuit video and installation art of the early 1970's. Artists of the time experimented not only with "narcissism, but with temporal and spatial displacements of body and its image that reveal the gap between a body and its imaginary self or "identity." Sermon's work is the site of a collective imaginary, a public "family" reunion, albeit as a surreal composition of bodies without a counterpart in physical reality, akin to the condensations Freud identified in dreams. What the "live" mixture of bodies in Sermon's work exposes is the far from explored field of human relations as they have become inflected with and transformed by technology." [4]

\section{Location, Location, Location}

Emotional exchange in the telematic space is highly dependent on location and interface. Whilst I have chosen to use the bed or sofa as a meeting place, other artists in the field of telematic arts have relied purely on the dynamics site specificity. In the seminal telematic installation "Holein-Space”, produced by Kit Galloway and Sherrie Rabinowitz, in 1980, geographically remote public audiences were instantly transformed into performers in the first networked narrative performance in a social context of its kind. What initially appears to be a random choice of locations for this public intervention - from the point of view of the user/actor, becomes increasingly apparent that the artists chose theses cities and locations for very specific social and political reasons, creating a networked narrative within an extremely dynamic context. Kit Galloway and Sherrie Rabinowitz describe the work as follows. 
"HOLE-IN-SPACE was a Public Communication Sculpture. On a November evening in 1980 the unsuspecting public walking past the Lincoln Centre for the Performing Arts in New York City, and "The Broadway" department store located in the open air Shopping Centre in Century City (LA), had a surprising counter with each other.

Suddenly head-to-toe, life-sized, television images of the people on the opposite coast appeared. They could now see, hear, and speak with each other as if encountering each other on the same sidewalk. No signs, sponsor logos, or credits were posted -- no explanation at all was offered. No self-view video monitors to distract from the phenomena of this life-size encounter. Selfview video monitors would have degraded the situation into a self-conscience videoconference.

If you have ever had the opportunity to see what the award winning video documentation captured then you would have laughed and cried at the amazing human drama and events that were played out over the evolution of the three evenings. Hole-In-Space suddenly severed the distance between both cities and created an outrageous pedestrian intersection. There was the evening of discovery, followed by the evening of intentional word-of-mouth rendezvous, followed by a mass migration of families and trans-continental loved ones, some of which had not seen each other for over twenty years." [5]

"Hole-In-Space” relies on the US cultural cliché of the east coast - west coast indifference. Confronting the pedestrian passes-by in New York and Los Angeles and brining them up on a telematic stage to tell jokes " Question: how many New Yorkers does it take to change a light-bulb? Answer: None of your fucking business", sing songs “New York, New York” and play games charades on one occasion. Viewers were instantly transformed into performers in an east coast meets west coast soap opera.

In continuing to focus on location or stage set I would like to turn to the monumental figure of Sergei Eisenstein. However, not in reference to his films, but of his lesser know theatre productions with the Proletcult Theatre in the 1920's. This was one of the most influential periods of his career - firstly as a theatre designer and later as director after having studied at the Directors Studio of Vsevolod Meyerhold in 1921. This is where most of the issues relevant to my argument were developed, described in his "Mon-tage of Attractions"; which established a new principle of dramaturgy, producing extremely strong effects on the audience by means of combining posters, slogans, circus, variety show, gymnastics, scenery and theatre effects. In 1923 Eisenstein staged "Gas Masks", a play about the employees of a gasworks, where he actually moved the play entirely out of the theatre and staged it in the Moscow Gas Factory. The play, which depicted life in the gas factory, ended each performance as the new shift came to work - thereby breaking the bounds of theatre in very similar ways to our current experiments with network narrative structures. Although Eisenstein considered it to be a failure in terms of film/theatre realism, his intention to embody the viewer within the performance is entirely that of my own work in which I consider the site-specific nature of the stage set to be of paramount importance in the telematic installation. Eisenstein described the performance in his notes.

"In Gas Masks we see all the elements of film tendencies meeting. The turbines, the factory background, negated the last remnants of make-up and theatrical costumes, and all elements appeared as independently fused. Theatre accessories in the midst of real factory plastics appeared ridiculous. The element of 'play' was incompatible with the acrid smell of gas. The pitiful platform kept getting lost among the real platforms of labour activity." [6]

\section{A Body of Water}


Eisenstein's use of the Moscow Gas Factory as a determining social narrative context brings me back to my own work, and one particular installation that I produced in collaboration with Andrea Zapp in 1999, entitled “A Body of Water”. Similarly to Eisenstein's “Gas Works” this installation was entirely situated in a disused coalminers changing and shower room, and is also relying on the sound and smell of coal dust and running water in order to determine the context of telepresent showering and the users/actors performance within it. Commissioned and produced for the "Connected Cities" exhibition "A Body of Water" connected three sites in one single telematic space. Live video images of the gallery visitors at the "Wilhelm Lehmbruck Museum” in Duisburg Germany were chroma-key mixed with images of visitors standing in the changing rooms at the nearby disused "Ewald/Schlaegel und Eisen" colliery in Herten. The video image of the combined audiences was simultaneously back projected onto a fine wall of water in the shower room, referred to locally as the "Waschkaue", providing a third interactive space - literally by walking through and touching the projected participants in the water - who were connected by a video camera that distributed real-time images of the water screen projection to all three sites at once. The water screen itself had the advantage of working as a $10 \%$ front projection and $90 \%$ back projection, allowing us to project two separate images simultaneously from either side of the water. As the audience entered the Waschkaue space they were faced by life size projections of the public floating "live" in a pool of mist and vapour in the centre of the blacked-out shower room. Moving around towards the back of the space they were confronted again by life size images of naked coalminers (projected documentary video footage) showering just as they once did in the very same Waschkaue. In this collaborative installation with Andrea Zapp it was our intension utilise the sitespecific sounds and smells of this context in order to develop and reinstate the ceremonial like camaraderie taking place amongst the showering miners in the form of "buckling" - a local coalminers term for washing the back of a fellow miner. "A Body of Water" allowed our live performing spectators to rein-act and experience this simple, yet complex act in the form an openended narrative.

\section{Peace Talks}

The final work I will discuss is entitled "Peace Talks" and was commissioned by FACT Liverpool for the BitParts Exhibition at Worcester City Art Gallery in February 2003. In this installation I take the theme of the United Nations negotiations room as its determining narrative environment. Needless to say under the political climate of the time the participants fully engaged and debated issues concerning what was then the looming invasion of Iraq. Again by chromakeying two remote sites the performers shared the same telepresent space, but in this particular installation I chose to construct two identical environments based on Professor Ames' 1960's distorted room experiment - onto which an "Unreal” computer game model of a United Nations negotiations room was mapped. The two users were placed within a shared telepresent UN environment - four walls and table. However, one participant appeared to be a great deal smaller than the other and when walking around the room their scale altered in accordance with the monocular perspective of the Ames room optical illusion. In addition to this disorientating perception of space the immersive nature of this piece was further enhanced by the use of head mounted displays that physically denied the user/actor any visible connection to the outside installation space. The two performers no longer had the ability to control their movements in distant monitors as in previous installations; instead they viewed their movements via the fixed camera position alone. In effect - removing their eyes from their head and investing them solely within the camera on which they have to rely to navigate within the space, resulting in complete telepresent immersion. - As one participant exclaimed after 20 minutes of dialogue "I've just realised I'm talking to myself here, people outside must be wondering what an earth is going on”. For such an installation theme and context to function as an open narrative structure I was forced to introduce the capability of speech, which was exploited to the point that participants began to lose the sense and importance for time, place and other appointments. Complete strangers were 
desperate to talk and share there feelings about the looming situation for up to half an hour on occasions, making comments such as "I feel I could make some decisions here that would be viewed later as quite uncharacteristic"

\section{A topology of body and space}

In drawing towards a conclusion now I would like to back track slightly to some of my original telematic interfaces and use a quote from Machiko Kusahara, referring to the topology of body and space in my telematic performance, specifically the bed interface included in "There's no simulation like home” which was first realised as "Telematic Dreaming” in 1992 in Finland.

"Within this series of works that employ the teleconference mechanism Telematic Dreaming surely has the most powerful impact because of the dissimilating effect of the bed, a sign shared by everyone. By putting audience participants in that familiar situation from TV drama of getting into bed with someone one has just met, this work drives one, or the member of the audience before one's eyes (the performer), into a state of bewilderment. Members of the audience are placed in the positions of the actor who plays out a bed scene on stage or before a camera, or the voyeur who peeps in on the acts of others. This is a secret act taking place in a public space, and that public space is a virtual space that does not exist in reality. Furthermore, despite the fact that the body is the only means of communication therein, the body of the other party is ghost-like, without substance. This contradictory situation not only confounds the audience, but also, after first releasing them from the logic and restrictions of daily life and dismantling the various elements of signatory identity and the biological environment of the body, it enables experimentation with and enjoyment of the role the body plays in communication. The virtuality of the space enables it to maintain both theatrically and the context of daily life at the same time. In the interstice between material physicality and an informational space in which electronic signals collide, Sermon reverses the meanings and sensibilities tied to daily life and provides us with an opportunity to think about the essence of communication." [7]

Machiko Kusahara sums up my entire paper in this single quote. As she points out the telepresent body is both simultaneously present and yet virtual at the same time. In the context of daily life as represented in "There's no simulation like home” we slip back and fourth between the roles of performer and viewer and here we return to Lacan and his mirror stage - an observation my own daughter made a few weeks ago when she told me about her new friend who has the same colour hair as her, the same clothes as her and the same name as her. When I asked her where her friend is, it was "Lacan's mirror" that she showed me.

“... he experiences in play the relation between the movements assumed in the image and the reflected environment, and between this virtual complex and the reality it reduplicates - the child's own body, and the persons and things around him." [8]

\section{The double consciousness of the performer/user}

What actually made Telematic Dreaming most successful for me, was not the latest ISDN or Internet videoconferencing technology of its time, but the interface - the bed. The bed was the most psychological charged complex piece of "technology" in that whole piece. Perhaps today I am still looking for other such interfaces that function, just like the bed - as a portal between the human avatars we control as performers inside the matrix and ourselves. This dilemma aside - my ultimate aspiration is as always to go beyond the keyboard and screen based interface and experience telematic communication within an immersed telepresent environment. 
In January 2001 I exhibited Telematic Dreaming at the Wroclaw Media Festival in Poland, for the twenty-first time since its realisation in 1992. Due to certain technical complications I was forced to exhibit the two beds in the same exhibition space, they where placed 25 meters apart across an open gallery space making it possible to have sight of the other bed. This was the first time ever that the two participants/performers where able to see each other in both a present and telepresent state simultaneously. The acute feeling of having two bodies in this installation set up was extremely alarming; by simply placing my hand on a pillow on one bed it was simultaneously placed on another bed 25 meters in front of me. The experience brought pure clarity to the notion of a double consciousness that Roy Ascott defines as

"The state of being which gives access to two distinctly different fields of experience, or two distinctly different views of the same event, or two separate or remote locations, at one and the same time.” [9]

Or that of being two distinctly different telematic experiences as performer and user. 


\section{Bibliography}

[1] - Andrea Zapp, “net.drama://myth/mimesis/mind_mapping/”, New Screen Media -

Cinema/Art/Narrative, Martin Rieser, Andrea Zapp, (eds.), BFI, London, 2002, p. 83.

[2] - Daniel C. Dennett, Consciousness Explained, Viking, London, 1992, p. 47.

[3] - Jacques Lacan, “The Mirror Stage”, Écrits: a selection, Routledge, London, 1989, p. 2. (First published: Écrits, Éditions du Seuil, Paris, 1966)

[5] - http://www.ecafe.com/getty/HIS/ (20.07.03)

[6] - Sergei Eisenstein, Film Form - Essays in Film Theory, Translated and Edited by Jay Leyda, Harvest Books, New York, 1972, p. 16.

[7] - Kusahara, Machiko, “A Topology of Body and Space”, The Museum Inside The Network, ICC/NTT Publishing, Tokyo, 1995, p. 127.

[8] - Jacques Lacan, “The Mirror Stage”, Écrits: a selection, Routledge, London, 1989, p. 2. (First published: Écrits, Éditions du Seuil, Paris, 1966)

[9] - Roy Ascott “Gesamtdatenwerk. Connectivity, Transformation and Transcendence”, Ars Electronica: Facing the Future, MIT Press, Linz, 1998, p. 87.

\section{Biography}

\section{Paul Sermon - Professor of Creative Technology}

He School of Art \& Design, The University of Salford

Email: p.sermon@salford.ac.uk URL: http://www.paulsermon.org

Born 1966. BA Hon's Fine Art, Gwent College of Higher Education, 1988. MFA, The University of Reading, 1991. Awarded Prix Ars Electronica “Golden Nica” Linz, Austria, 1991. Artist-inResidence, ZKM Centre for Art and Media Karlsruhe, Germany, 1993. Awarded Interactive Media Festival "Sparkey Award” Los Angeles, 1994. Dozent for Telematic Arts at the HGB Academy of Visual Arts in Leipzig, Germany, 1993 to 1999. Guest Professor for Performance and Environment, University of Art and Industrial Design Linz, Austria, 1998 to 2000. Since June 2000 based at The University of Salford in the research field of immersive and expanded telematic environments. 